\title{
Estimated prevalence of people with learning disabilities: template for general practice
}

Victoria Allgar, Ghazala Mir, Joyce Evans, Joyce Marshall, David Cottrell, Phil Heywood and Eric Emerson

\begin{abstract}
\section{Background}

In 2001, a white paper set out a commitment to ensure that people with a learning disability receive equal access to health services, with an expectation that general practices would have identified all people with a learning disability registered with the practice by June 2004 .

\section{Aim}

To outline the development of a template to create practice-based registers of people with learning disabilities in general practice.

\section{Design of study}

The study was prospective, employing a template to identify patients in general practice with a learning disability. The study used capture-recapture methodology to estimate the prevalence of learning disability in the population.

\section{Setting}

General practices in Leeds.

Method

A template was developed that uses Read code searches of practices' electronic medical records, along with practice knowledge to identify patients who have a learning disability.

\section{Results}

The tool was piloted in $\mathbf{3 0}$ general practices in Leeds and validated against a city-wide database of people with learning disability. There was a wide variation between the practices in terms of how many people were identified, with the average being $0.4 \%$ of the practice population. Combined with validation from the city-wide database, this increased to $0.7 \%$.

\section{Conclusion}

The template provides a valuable tool for general practices to begin developing a practice-based register of patients with a learning disability. This is particularly timely in view of the revised General Medical Services contract Quality and Outcomes Framework indicator, stimulating practices to produce a register of patients with learning disability. Use of a common definition for learning disability is needed to improve consistency in identification across practices.
\end{abstract}

\section{Keywords}

general practice; learning disabilities; prevalence; register.

\section{INTRODUCTION}

Research has demonstrated that people with learning disability have greater health needs and poorer health outcomes than the general population. ${ }^{1,2}$ Despite higher rates of mortality and morbidity, they experience shortfalls in the provision of and access to health care. ${ }^{3,4}$ Identification of people with learning disability in primary care is an important prerequisite to improving access and to preventative strategies such as health checks:5,6 key themes in recent public health policy. ${ }^{7.8}$

In 2001 the government white paper, Valuing People: A New Strategy For Learning For The 21st Century set out a commitment to ensure that people in England with learning disability receive equal access to services, such as health, education, employment, and leisure. ${ }^{9}$ The condition was defined as being present from childhood and involving 'a

V Allgar, BSc (Hons), CStat, PhD, senior lecturer, Hull and York Medical School; J Marshall, SRN, RM, BSc, MPH, PhD, lecturer, Department of Health Sciences, University of York, York; D Cottrell, MA, MB, ChB, FRCPsych, professor of child and adolescent psychiatry, Academic Unit of Psychiatry and Behavioural Sciences; P Heywood, MB, ChB, FRCGP, DCH, $D R C O G$, Emeritus professor of primary care, University of Leeds; G Mir, PGCE, PhD, senior research fellow, Centre for Health and Social Care, Institute of Health Sciences, Faculty of Medicine, University of Leeds; J Evans, BA, MA (Hons), SRN, DN, research assistant, Rothwell Health Centre, Leeds.

E Emerson, BSc (Hons), MSc, PhD, professor of disability and health research, Institute for Health Research, Lancaster University, Lancaster.

Address for correspondence

Dr Ghazala Mir, Centre for Health and Social Care, Institute of Health Sciences, Charles Thackrah Building, University of Leeds, 101 Clarendon Road, Leeds LS2 9LJ. E-mail: G.Mir@leeds.ac.uk

Submitted: 10 September 2007; Editor's response: 9 November 2007; final acceptance: 15 January 2008. (B) British Journal of General Practice 2008; 58: 423-428. DOI: 10.3399/bjgp08X299272 


\section{How this fits in}

People with a learning disability have greater heath needs and poorer health outcomes than the general population, and have been specifically targeted in public health policy. Estimates of the prevalence of learning disabilities vary substantially, and range from $0.23 \%$ to $3.0 \%$, depending on the definition of learning disability and data sources used. In 2001, a white paper set out a commitment to ensure that people with learning disability receive equal access to health services with an expectation that general practices would have identified all people with a learning disability registered with the practice by June 2004. This paper outlines the development of a template which is a valuable tool for general practices to begin developing a practice-based register of patients with learning disability. practices could use electronic medical records to identify patients with learning disability, and to produce a register from this information. This study also highlights issues relevant to estimating prevalence of this population that were highlighted during development and validation of the template.

\section{METHOD}

\section{Development of the template}

Five GP practices were asked to identify patients with learning disability; no further guidance was given other than to consider patients living in group homes, or hostels for people with learning disability. A variable response highlighted several problems with data collection and quality, both generally and more specifically relating to learning disability: not all practices could identify all their patients. Transfer from paper to electronic records and summarising or coding data varied greatly between practices, and no standard definition of learning disability had been used. These factors influenced the development of the template, reinforcing the need for a multitargeted approach to identifying patients with learning disability, and a consistent definition of learning disability.

A list of codes from the problem page of electronic records of those patients identified as having learning disability was supplemented by advice and information about coding for learning disability from the Read formulary, Department of Health, and Primary Care Information Service (PRIMIS+). The first practice had intentionally coded people with learning disability with an E3 code, retaining the original diagnoses/codes in the problem section of the patients' electronic medical record. From this it was possible to capture and categorise three broad categories of codes that were 'ascribed' to people with learning disability before the E3 was added: checks for people with learning disability. ${ }^{8}$ The Equality and Human Rights Commission (formerly the Disability Rights Commission) has also recommended that practices establish registers to meet their legal responsibilities of working towards equal outcomes for people with disability. ${ }^{4,12}$

The Institute of Health Sciences at Leeds University was commissioned by the Department of Health to evaluate the impact of government health targets on the healthcare experience of people with learning disability. Part of this study involved the creation of a Leeds-wide database of people with a learning disability, drawing on the knowledge of health, community care, and voluntary organisations.

The need for an identification tool became apparent early in the research process. This study describes the development of a template for identification of people with learning disability in general practice. It investigates how general
- codes that relate to diagnoses;

- codes that relate to functional ability, which may be a description of a level of intelligence or of social functioning; and

- codes relating to appropriate referrals or learning disability assessment.

Although the E3 Read code was not routinely used in the remaining practices, more codes within these three categories were found by searching for codes used and identified in the previous practice, and by searching for addresses (small group homes/hostels for people with learning disability). This iterative approach resulted in a substantial number of codes that could be used in searches of practice computer systems for people with learning disability. The number was reduced by a process of identifying a 
Table 1. Number (\%) of patients identified by the Leeds-wide database and the practice template.

\begin{tabular}{lccc} 
& $\begin{array}{c}\text { Total patients, } n(\%), \\
\text { from } 17 \text { practices that } \\
\text { applied the full version } \\
\text { of the template }\end{array}$ & $\begin{array}{c}\text { Total patients, } n \text { (\%), } \\
\text { from 13 practices that } \\
\text { applied the shortened } \\
\text { version of the template }\end{array}$ & $\begin{array}{c}\text { Total patients, } \\
n(\%) \text {, identified }\end{array}$ \\
\hline $\begin{array}{l}\text { Number of patients identified from each source } \\
\text { Leeds-wide database }\end{array}$ & $663(73)$ & $393(78)$ & $1056(74)$ \\
Practice template & $571(62)$ & $281(56)$ & $852(60)$ \\
\hline Cross reference 'Leeds-wide database' and 'practice template' & & \\
Leeds-wide database only & $343(38)$ & $227(45)$ & $570(40)$ \\
Practice template only & $251(27)$ & $111(22)$ & $362(25)$ \\
Both lists & $320(35)$ & $168(33)$ & $488(34)$ \\
Total & 914 & 506 & 1420 \\
Prevalence & & & \\
Practice list size & 136700 & 81851 & 218551 \\
Total & $900(0.66)$ & $498(0.61)$ & $1398(0.64)$ \\
Leeds-wide database & $661(0.48)$ & $393(0.48)$ & $1054(0.48)$ \\
Practice template & $558(0.41)$ & $273(0.33)$ & $831(0.38)$ \\
\hline
\end{tabular}

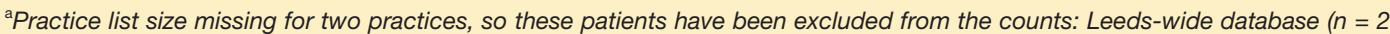
patients), and the practice template ( $n=21$ patients).

higher code where possible.

The three categories of codes included many clinical terms that did not necessarily indicate a learning disability. A balance had to be struck between including all those codes that might be associated with learning disability, with the concurrent resources required to verify the list, against leaving out codes and the risk of 'missing' some patients with learning disability. A balance was struck between including syndromes that do not necessarily cause learning disability, yet are syndromes with a prevalence of at least 1 in 15000 , and excluding rarer conditions that have a definite association with learning disability. Disorders specifically listed in a pilot guide to health facilitation for GP practices, created by a local primary care trust (PCT), were also included in the template.

Subsequent piloting also highlighted codes where the numbers of possible patients identified were so high that verification would have been too time consuming. For example, codes that relate to difficulties, problems, or general delays in respect of learning ability, behaviour, specific, and general development can include many people who do not have learning disability. E2F (Specific delays in development), and ZV2[V] (Encounter due to reproduction and development problems) were omitted from the template for this reason. Due to the sometimes preferred terminology of 'learning difficulty', the code 13Z4E was retained, despite the potential for including many patients who do not have learning disability. The code for learning disability, Eu81z-1, was omitted because some computer systems can only search on the higher code Eu81z ( $[\mathrm{X}]$ Developmental disorder of scholastic skills unspecified), which is not learning-disability specific. A similar problem emerged with the use of the code for global delay E2F5-1, hence its exclusion despite widespread use in past medical records.

The final template (Appendix 1) includes:

- the white paper definition of learning disability;

- a list of codes that give a definite indication of a learning disability, for example, E3\% (Mental retardation), PJO\% (Down's syndrome), 9HB\% (Learning disabilities administration status);

- a list of codes that give a possible indication of a learning disability and need to be verified by the patients' GP, for example, 13Z4E (Learning difficulties), Eu845 ([X] Asperger's syndrome), 1J9 (Suspected autism), F23\% (Congenital cerebral palsy);

- patients who live in a group home specifically for people with learning disability, identified by searching by group home address; and

- recollection from memory by GPs of patients with learning disability that may be known to the practice.

\section{Validation of the template}

All 120 practices across the city, from the five PCTs were asked to apply the template to their practice population. Table 1 shows the number of patients identified using the full and shortened version of the template. In total 30 (25\%) practices replied: 17 practices applied the full template as detailed in Appendix 2. The remaining 13 applied the shortened version of the template, which included only the codes that give a definite indication of a learning disability. This was because this version was easy to run off their computer systems and did 
not need validation by the practice required for 'possible codes'.

As part of the wider study, a Leeds-wide database of people with learning disability was developed by obtaining details of people with learning disability from social services, PCT-led services (such as therapy services and dietetics), education, the mental health trust, and voluntary sector organisations. The West Yorkshire Central Services Agency computer system was searched for each person on the database, to establish their registration with a GP. This provided a validation of the GP template list.

\section{RESULTS}

A total of 1420 patients were identified as having learning disability from the 30 practices (Table 1). Of these, $60 \%$ were identified by the practice template, with variations between practices ranging from $11 \%$ to $100 \%$. The Leeds-wide database identified $74 \%$ of the total number identified, with variations between practices of $0 \%$ to $97 \%$.

One-quarter of patients were identified by the practice alone, one-third by both lists, and 40\% ( $n$ $=570$ ) by the Leeds-wide database alone (Figure 1). There was no significant difference between practices that applied the full template, and those that applied the short template.

A total of 852 patients were identified using the template. Of these, 488 (57\%) were also identified on the Leeds-wide database. There were variations between practices ranging from $0 \%$ to $100 \%$. For the practices that applied the full template, the average proportion was $46 \%$, compared to $57 \%$ for those who applied the short template. This was not a significant difference $(t(28)=2.05, P=0.334)$.

On the Leeds-wide database, 4589 patients were identified and 1056 (23\%) were identified as being registered with one of the 30 practices. Of these, $46 \%$ were also identified by the practices. There were variations between practices ranging from $0 \%$ to $100 \%$. For the practices that applied the full template, the average proportion was $41 \%$,

Figure 1. Venn diagram of the overall number of patients identified by the Leeds-wide database and the practice template. compared to $34 \%$ for those who applied the short template. This was not a significant difference $(t(28)$ $=2.05, P=0.357$ )

\section{Estimate of prevalence}

As shown in Table 1, the proportion of the practice population identified by the template alone was $0.38 \%$. This varied between practices from $0.3 \%$ to $1.0 \%$. When combined with those patients identified from the Leeds-wide register, the proportion of the practice population increased to $0.64 \%$.

Capture-recapture techniques can be used to estimate prevalence and completeness of registers..$^{11,12}$ This technique, originally developed to estimate the size of animal populations, enables a defined population to be estimated by using two or more sources of cases. The number of individuals in each sample, and those common to both, are used to estimate the total population assuming that the two sources are independent of each other. ${ }^{13,14}$

Capture-recapture analysis gave an estimated total population size of 1843 (95\% confidence interval $[\mathrm{Cl}]=1765$ to 1921 ), with an estimated 423 missed by both sources (Appendix 3). ${ }^{15}$ This represents a prevalence of learning disability of $0.84 \%$ of the total practice populations $(95 \% \mathrm{Cl}=$ $0.81 \%$ to $0.88 \%$ ).

Capture-recapture analysis was also undertaken for each individual practice. The estimated prevalence varied between practices from $0.2 \%$ to $3.7 \%$. For practices that applied the full template, the average prevalence rate for learning disability was $1.14 \%$, compared to $0.83 \%$ for those that applied the short template. This was not a significant difference $(t(28)=2.05, P=0.245)$.

\section{DISCUSSION}

\section{Summary of main findings}

The paper has outlined the process and validation of a template for identifying patients in general practice who have a learning disability. The template provides a practice-sourced list of people with a possible diagnosis of learning disability. It is a tool that can be used by non-clinical staff to carry out quick and accurate searches in order to start the process of identifying patients with a learning disability.

\section{Strengths and limitations of the study}

The template cannot provide a definitive list of patients in general practice who have a learning disability. The use of the full template is likely to produce a list that includes people who do not have a learning disability, and a process of verification is required. The necessary verification of learning disability is not a quick or straightforward process; it requires GP and practice staff time and may 
involve multidisciplinary collaboration. However, there is evidence that once the process has been completed practice staff report that maintaining a register is relatively straightforward..$^{13}$

Combining information from practice lists with the data from the city-wide database more than doubled the number of people identified on practice lists, and identified 1422 patients registered with one-quarter of practices. This suggests that the template will need to be combined with other sources of information to produce a more accurate list. The findings, combined with current evidence, ${ }^{16,17}$ suggest that a combination of Read-code identification, practicebased knowledge, and the input of learning disability professionals will produce the most accurate registers.

However, cross-referencing with other data sources revealed that the template was not identifying all the people known to other organisations. There was wide variation between the practices in terms of how many people were identified, with the average being around $57 \%$, but ranging from $0 \%$ to $100 \%$ captured. Qualitative evidence from the wider study suggests that there may be a number of reasons for this.

The definition of learning disability is likely to have varied by organisation. ${ }^{14,15}$ Although the research team promoted the white paper definition, concerns about labelling and stigma could have affected collation of the final practice list. ${ }^{16}$ Further reasons may relate to patients who have recently moved into the practice, patients who have been miscoded on the system, and the variable quality of electronic patient records in terms of completeness and accuracy of information. ${ }^{18}$ In addition, patients may have been classified as having a learning disability by one of the organisations contributing to the city-wide database, but not by the GP.

The template separates the two categories of code: those that represent a definite indication of a learning disability, and codes that give a possible indication of a learning disability, but would need verification from the GP. An initial register based on those codes that indicate a definite learning disability will be relatively quick to verify. In the revised General Medical Services contract (GMS), ${ }^{10}$ the Quality and Outcomes Framework (QOF) indicator stimulates practices to produce a register of patients with learning disability (4 points). However, this does not appear to require validation of the completeness of the practice register; practices that only use the shorter template to develop a practice register will get the same QOF points as practices that strive for more accurate information. This raises the question of how to assess the completeness of the register.

Coding of learning disability may be based on information contained in a patient's medical records from many years ago. Usually there will be no indication in the summarised computer record of the source of this information or the definition of learning disability used. Nor is there any way of knowing from the primary care information systems if the identification has been verified recently using the white paper criteria for learning disability. ${ }^{9}$

It is important that once GP practices have started the process of developing a register, an agreed, consistent code for learning disability is used. The lengthy process of identifying people in the practice population with a learning disability through the use of the template and professionals' assessment should be a one-off exercise with subsequent additions to practice lists assessed during registration of new patients. It may be deemed good practice to include the source of the assessment of learning disability in the patient's electronic patient record.

There are ethical considerations surrounding patient knowledge and agreement to inclusion on a register of patients with learning disability. In some cases, patients may never have been aware of being labelled. Conditions with clear diagnostic features, such as diabetes, have higher-quality recording than conditions with more subjective criteria. ${ }^{19}$ Collaborative working with learning disability services and organisations representing people with learning disability may be one way of addressing this barrier.

\section{Comparison with existing literature}

Whitaker's review of prevalence studies notes wide variations in estimated prevalence related to the definition of learning disability and data sources used. ${ }^{17}$ Where data are taken only from existing users of learning disability services, studies report between $0.23 \%$ and $0.29 \%$ of the population are registered as having a learning disability. Where the dual criteria of intellectual and adaptive functioning are adopted - as in the white paper - the best evidence suggests prevalence is likely to be around $2 \%$ of the population - with $0.46 \%$ known to learning disability services..$^{20}$ Using IQ tests alone brings prevalence rates closer to $2.5 \% .^{17}$ Confusingly, the white paper quotes this higher prevalence rate alongside the dual criteria definition. $^{9}$

The template identified $0.38 \%$ of the population of patients at $25 \%$ of Leeds practices. The population of Leeds, the fieldwork area, is estimated at $715404 .{ }^{21}$ Based on estimated prevalence of $2 \%$, the total expected population of 
people with learning disability in Leeds is 14 300. If applied across Leeds it would be reasonable to expect to identify approximately 3400 patients with learning disability. This is $24 \%$ of the expected population. Elsewhere, the success of tools used to identify people with learning disability has been as low as $0.1 \%$ of the expected population, ${ }^{22}$ and $0.001 \%,{ }^{13}$ although in the latter study there was considerable variation between practices.

\section{Implications for future research and clinical practice}

There is no nationally recognised code for learning disability for use in general practice. The Department of Health has recommended the use of E3 to code learning disability, while recognising at the same time a widespread reluctance to use a code for 'mental retardation', as it is an out-of-date term that is not accepted by many people with learning disability. It has advised those who want to use a consistent code, but who do not wish to use E3, to come to a local agreement with PRIMIS+, to enable local auditing of access to health care. ${ }^{23}$ The NHS Centre for Coding and Classification advises that Eu codes are used in preference to E3 codes. In ICD-10, mental retardation and learning disability are classified as separate entities: E3 and 9HB respectively. A proposal to relax the meaning of learning disability was rejected.

The template provides a valuable tool for general practices to develop a practice-based register of patients with a learning disability, and appears to identify more people with learning disability than methods currently being used elsewhere. ${ }^{13,17}$ This is particularly timely in view of the revised GMS contract and QOF indicator stimulating practices to produce a register of patients with learning disability. Although not a solution to the health inequalities experienced by people with learning disability, such identification is an important first step to planning and providing appropriate health care as envisaged in the white paper.

\section{Funding body}

Department of Health, Policy Research Programme (learning Disability Research Initiative): 'Health Facilitation and Learning Disability: Evaluating the role of health facilitators'

\section{Ethical approval}

Ethics approval was given by REC: Harrogate, (04/Q1107/1)

Competing interests

The authors have stated that there are none

Discuss this article

Contribute and read comments about this article on the Discussion Forum: http://www.rcgp.org.uk/bjgp-discuss

\section{REFERENCES}

1. Krahn GL, Hammond L, Turner A. A cascade of disparities: health and health care access for people with intellectual disabilities. Ment Retard Dev Disabil Res Rev 2006; 12(1): 70-82.

2. Ouellette-Kuntz H. Understanding health disparities and inequities faced by individuals with intellectual disabilities. J Appl Res Intellect Disabil 2005; 18(2): 113-121.

3. Sutherland G, Couch MA, Iacono T. Health issues for adults with developmental disability. Res Dev Disabil 2002; 23(6): 422-445.

4. Disability Rights Commission. Equal treatment: closing the gap. London: Disability Rights Commission, 2006.

5. Lindsay P, Burgess D. Care of patients with intellectual or learning disability. Br J Gen Pract 2006; 56(523): 84-86.

6. Baxter $\mathrm{H}$, Lowe $\mathrm{K}$, Houston $\mathrm{H}$, et al. Previously unidentified morbidity in patients with intellectual disability. Br J Gen Pract 2006; 56(523): 93-98.

7. Department of Health. Choosing health. London: The Stationery Office, 2004.

8. Department of Health. Our health, our care, our say. London: The Stationery Office, 2006

9. Department of Health. Valuing people: a new strategy for learning for the 21st century. London: The Stationery Office, 2001.

10. Einfeld S, Emerson E. Intellectual disabilities. In: Rutter M, Bishop D, $\mathrm{D}$ Pine D, et al (eds). Rutter's child and adolescent psychiatry. 5th edn. Oxford: Blackwell, 819-839.

11. Prasher V. Epidemiology of learning disability and comorbid conditions. Psychiatry 2003; 5(9): 302-305.

12. NHS Employers and General Practitioners Committee. Revisions to the NHS contract: 2006/7: delivering investment in general practice. www.nhsemployers.org http://www.bma.org.uk/ap.nsf/Content/revisionnGMSFeb20062 (accessed 27 Mar 2008).

13. Alborz A. The role of health checks in improving access to mainstream NHS healthcare services for people with learning disabilities. London: National Primary Care Research and Development Centre, 2005.

14. Mir G, Allgar V. Cottrell D, et al. Health facilitation and learning disability. Leeds: Centre for Health and Social Care, University of Leeds, 2007.

15. Mir G. Meeting valuing people health targets. Br J Learn Disabil 2007; 35(2): $75-83$.

16. Linehan C, Walsh PN, Van Schrojenstein H, et al. POMONA: health indicators for people with intellectual disability in the member states. Maastricht, 2006

http://www.pomonaproject.org/1_people_member_states.pdf (accessed 21 Jan 2008).

17. Whitaker S. Hidden learning disability. Br J Learn Disabil 2004; 32(3): 139-143.

18. Hassey A. Gerrett D. Wilson A. A survey of validity and utility of electronic patient records in a general practice. BMJ 2001; 322(7299): 1401-1405.

19. Jordan K, Porcheret M, Croft P. Quality of morbidity coding in general practice computerized medical records: a systematic review. Fam Pract 2004; 21(4): 396-412.

20. Emerson E, Hatton C. Estimating the current need/demand for supports for people with learning disabilities in England. Lancaster: Institute for Health Research, Lancaster University, 2004.

21. The 2001 Census in England and Wales. London: Office for National Statistics, 2001. http://www.statistics.gov.uk/census2001/ census2001.asp (accessed 21 Jan 2008).

22. Westminster PCT. A framework to address the health inequalities of people with learning disabilities in Westminster. London: Westminster PCT, 2006.

23. Valuing People Support Team. Update on Read Codes. UK: Care Services Improvement Partnership. http://valuingpeople.gov.uk/ dynamic/valuingpeople144.jsp (accessed 21 Jan 2008). 


\section{Appendix 1. Template for identifying patients with a learning disability in primary care: practice-based registers.}

The definition of learning disability used is: 'A person with learning disabilities has a significantly reduced ability to understand new or complex information and a reduced capacity to cope independently. This condition is present from childhood and has a lasting effect on development."

\section{Read codes that give a definite indication of learning disability}

\begin{tabular}{llll}
\hline E3\% & Mental retardation & Eu7\% & {$[\mathrm{X}]$ Mental retardation } \\
6664 & Mental handicap problem & PJ0\% & Down's syndrome - trisomy 21 \\
PJyy2 & Fragile X chromosome & Eu842 & {$[X]$ Rett's syndrome } \\
PKy93 & Prader-Willi syndrome & PKy80 & Noonan's syndrome \\
9HB\% & Learning disabilities administration status & &
\end{tabular}

Read codes that give a possible indication of learning disability AND need to be verified by the patients' GP

\begin{tabular}{llll}
\hline Eu8Iz & {$[\mathrm{X}]$ Developmental disorder of scholastic skills unspecified } & $13 Z 4 \mathrm{E}$ & Learning difficulties \\
PJ7\% & Klinefelter's syndrome & F23\% & Congenital cerebral palsy \\
F1370 & Athetoid cerebral palsy & Eu845 & [X] Asperger's syndrome \\
PK5 & Tuberous sclerosis & PK61 & Sturge-Weber syndrome \\
B927 & Neurofibromatosis - Von Recklinghausen's disease & BBe1\% & [M] Neurofibromatosis NOS \\
E140\% & Infantile autism & Eu84\% & [X] Pervasive developmental disorders \\
1 J9 & Suspected autism & C301 & Phenylketonuria \\
PKy0\% & Multiple system congenital anomalies & E2F2 & Other specific learning difficulty \\
ZV400 & [V] Problems with learning & $13 Z 3$ & Low IQ \\
$8 \mathrm{HHP}$ & Referral to learning disability team & & \\
\hline
\end{tabular}

Group home: patients who live in a group home specifically for people with a learning disability, identified by searching by group home address. GP identification: In the pilot study, GPs identified some patients who were not found using the above Read code searches OR group home address searches. Please include any additional patients with a learning disability that may be known to the practice.

$0=$ zero. $\%$ = include all sub-codes.

(c) The University of Leeds 2008. This work can be used free of charge and for any purpose subject to: (1) Acknowledgement of the authors of this article.

(2) To the full extent allowed under English law, neither the University nor the authors accept any liability arising from your use of the work. 


\section{Appendix 2. Number of patients identified by template.}

\begin{tabular}{|c|c|c|c|c|c|c|c|c|c|c|c|}
\hline \multirow[b]{2}{*}{ Practice } & \multirow{2}{*}{$\begin{array}{c}\text { Type of } \\
\text { practice } \\
\text { template } \\
\text { applied }\end{array}$} & \multirow[b]{2}{*}{$\begin{array}{l}\text { Leeds-wide } \\
\text { database }\end{array}$} & \multirow[b]{2}{*}{$\begin{array}{l}\text { Practice } \\
\text { template }\end{array}$} & \multirow[b]{2}{*}{$\begin{array}{c}\text { Total } \\
\text { from } \\
\text { both lists }\end{array}$} & \multicolumn{3}{|c|}{$\begin{array}{c}\text { Cross reference Leeds-wide } \\
\text { database and practice template }\end{array}$} & \multicolumn{4}{|c|}{ Practice list size } \\
\hline & & & & & $\begin{array}{l}\text { Practice } \\
\text { only }\end{array}$ & Both lists & $\begin{array}{c}\text { Leeds-wide } \\
\text { database } \\
\text { only }\end{array}$ & $\begin{array}{c}\text { Total } \\
\text { practice } \\
\text { list size }\end{array}$ & $\begin{array}{c}\text { Template } \\
\text { by practice } \\
\text { list }\end{array}$ & $\begin{array}{l}\text { Leeds-wide } \\
\text { by practice } \\
\text { list size }\end{array}$ & $\begin{array}{l}\text { List } \\
\text { size }\end{array}$ \\
\hline & & $n(\%)$ & $n(\%)$ & $n$ & $n(\%)$ & $n(\%)$ & $n(\%)$ & $n$ & $\%$ & $\%$ & $\%$ \\
\hline P2 & Long & $20(56)$ & $20(56)$ & 36 & $16(42)$ & $4(11)$ & $16(47)$ & 5053 & 0.71 & 0.40 & 0.40 \\
\hline P3 & Long & $48(80)$ & 31 (52) & 60 & $12(20)$ & $19(32)$ & $29(48)$ & 9562 & 0.63 & 0.32 & 0.50 \\
\hline $\mathrm{P} 4$ & Long & $74(78)$ & $48(51)$ & 95 & $21(22)$ & $27(28)$ & $47(49)$ & 12212 & 0.78 & 0.39 & 0.61 \\
\hline P5 & Long & $140(83)$ & $122(72)$ & 169 & $29(17)$ & $93(55)$ & $47(28)$ & 22277 & 0.76 & 0.55 & 0.63 \\
\hline P6 & Long & $14(52)$ & $19(70)$ & 27 & $13(44)$ & $6(22)$ & $8(33)$ & 6703 & 0.40 & 0.28 & 0.21 \\
\hline $\mathrm{P} 7$ & Long & $75(86)$ & $47(54)$ & 86 & $11(14)$ & $36(41)$ & $39(45)$ & 15957 & 0.55 & 0.29 & 0.47 \\
\hline P9 & Long & $39(95)$ & $33(80)$ & 41 & $2(2)$ & $31(76)$ & $8(22)$ & 3277 & 1.25 & 1.01 & 1.19 \\
\hline P10 & Long & 18 (69) & 17 (65) & 26 & $8(31)$ & $9(35)$ & $9(35)$ & 6691 & 0.39 & 0.25 & 0.27 \\
\hline P11 & Long & $47(90)$ & $45(87)$ & 52 & $5(8)$ & $40(77)$ & 7 (15) & 6053 & 0.86 & 0.74 & 0.78 \\
\hline P12 & Long & $23(62)$ & $26(70)$ & 37 & $14(38)$ & $12(32)$ & $11(30)$ & 3671 & 1.01 & 0.71 & 0.63 \\
\hline P13 & Long & $22(58)$ & $17(45)$ & 38 & $16(42)$ & $1(3)$ & $21(55)$ & 5515 & 0.69 & 0.31 & 0.40 \\
\hline P14 & Long & 17 (89) & $2(11)$ & 18 & $1(11)$ & $1(5)$ & $16(84)$ & 7106 & 0.27 & 0.03 & 0.24 \\
\hline P15 & Long & 2 (14) & $13(93)$ & 14 & $12(86)$ & $1(7)$ & $1(7)$ & $\mathrm{n} / \mathrm{a}$ & - & - & - \\
\hline P16 & Long & $14(74)$ & $9(47)$ & 19 & $5(26)$ & $4(21)$ & $10(53)$ & 3828 & 0.50 & 0.24 & 0.37 \\
\hline P17 & Long & $11(48)$ & $15(65)$ & 23 & 12 (52) & $3(13)$ & 8 (35) & 3649 & 0.63 & 0.41 & 0.30 \\
\hline P18 & Short & $57(75)$ & $36(47)$ & 76 & $19(24)$ & 17 (22) & $40(54)$ & 10560 & 0.72 & 0.34 & 0.54 \\
\hline P19 & Short & $60(80)$ & $54(72)$ & 75 & 15 (17) & 39 (52) & 21 (31) & 12453 & 0.60 & 0.43 & 0.48 \\
\hline P20 & Short & $22(45)$ & $39(80)$ & 49 & 27 (49) & $12(24)$ & $10(27)$ & 7846 & 0.62 & 0.50 & 0.28 \\
\hline $\mathrm{P} 22$ & Short & $11(92)$ & $4(33)$ & 12 & $1(8)$ & $3(25)$ & $8(67)$ & 3864 & 0.31 & 0.10 & 0.28 \\
\hline P23 & Short & $15(94)$ & $6(38)$ & 16 & $1(6)$ & $5(31)$ & $10(63)$ & 9587 & 0.17 & 0.06 & 0.16 \\
\hline P24 & Short & 35 (97) & $15(42)$ & 36 & $0(3)$ & $15(42)$ & $20(56)$ & 6144 & 0.59 & 0.24 & 0.57 \\
\hline P25 & Short & 77 (80) & $54(56)$ & 96 & $20(20)$ & 34 (35) & $43(45)$ & 9630 & 1.00 & 0.56 & 0.80 \\
\hline P26 & Short & $18(72)$ & $15(60)$ & 25 & $5(20)$ & $8(32)$ & $12(48)$ & 6076 & 0.41 & 0.25 & 0.30 \\
\hline P27 & Short & 7 (88) & 1 (13) & 8 & $1(13)$ & $0(0)$ & 7 (88) & 2092 & 0.38 & 0.05 & 0.33 \\
\hline P28 & Short & $22(79)$ & $13(46)$ & 28 & $6(21)$ & $7(25)$ & $15(54)$ & 2107 & 1.33 & 0.62 & 1.04 \\
\hline P29 & Short & 21 (95) & $6(27)$ & 22 & $1(5)$ & $5(23)$ & $16(73)$ & 2537 & 0.87 & 0.24 & 0.83 \\
\hline P30 & Short & $0(0)$ & 8 (100) & 8 & 8 (100) & $0(0)$ & $0(0)$ & $\mathrm{n} / \mathrm{a}$ & - & - & - \\
\hline Total & & $1056(74)$ & $852(60)$ & 1420 & $364(26)$ & 488 (34) & $568(40)$ & 218551 & 0.64 & 0.38 & 0.48 \\
\hline
\end{tabular}




\section{Appendix 3. Capture-recapture analysis by practice.}

\begin{tabular}{|c|c|c|c|c|c|c|c|c|}
\hline Practice & Template & $\begin{array}{l}\text { Identified by } \\
\text { Leeds-wide } \\
\text { database, } n\end{array}$ & $\begin{array}{c}\text { Identified by } \\
\text { Leeds-wide } \\
\text { database and } \\
\text { practice template, } n\end{array}$ & $\begin{array}{l}\text { Identified } \\
\text { by practice } \\
\text { template, } n\end{array}$ & $\begin{array}{c}\text { Total identified } \\
\text { by combining } \\
\text { Leeds-wide } \\
\text { database and } \\
\text { practice template, } n\end{array}$ & Total, $^{a} n$ & Not found, ${ }^{\mathrm{b}} n$ & $\begin{array}{c}\% \text { of practice } \\
\text { population }\end{array}$ \\
\hline $\mathrm{P} 1$ & Long & 79 & 26 & 75 & 128 & 224 & 96 & 1.7 \\
\hline$\underline{\mathrm{P}} 2$ & Long & 20 & 4 & 20 & 36 & 87 & 51 & 1.7 \\
\hline$\underline{\mathrm{P} 4}$ & Long & 74 & 27 & 48 & 95 & 130 & 35 & 1.1 \\
\hline P5 & Long & 140 & 93 & 122 & 169 & 184 & 15 & 0.8 \\
\hline P6 & Long & 14 & 6 & 19 & 27 & 42 & 15 & 0.6 \\
\hline$\underline{\mathrm{P} 7}$ & Long & 75 & 36 & 47 & 86 & 98 & 11 & 0.6 \\
\hline P8 & Long & 20 & 7 & 32 & 45 & 86 & 41 & 0.7 \\
\hline P9 & Long & 39 & 31 & 33 & 41 & 42 & 1 & 1.3 \\
\hline $\mathrm{P} 11$ & Long & 47 & 40 & 45 & 52 & 53 & 1 & 0.9 \\
\hline$\underline{\mathrm{P} 12}$ & Long & 23 & 12 & 26 & 37 & 49 & 12 & 1.3 \\
\hline$\underline{\mathrm{P} 13}$ & Long & 22 & 1 & 17 & 38 & 206 & 168 & 3.7 \\
\hline$\underline{\mathrm{P} 14}$ & Long & 17 & 1 & 2 & 18 & 26 & 7 & 0.4 \\
\hline$\underline{\mathrm{P} 15}$ & Long & 2 & 1 & 13 & 14 & 20 & 6 & $\mathrm{n} / \mathrm{a}$ \\
\hline$\underline{\mathrm{P} 16}$ & Long & 14 & 4 & 9 & 19 & 29 & 10 & 0.8 \\
\hline P17 & Long & 11 & 3 & 15 & 23 & 47 & 24 & 1.3 \\
\hline P18 & Short & 57 & 17 & 36 & 76 & 118 & 42 & 1.1 \\
\hline P19 & Short & 60 & 39 & 54 & 75 & 83 & 8 & 0.7 \\
\hline P20 & Short & 22 & 12 & 39 & 49 & 70 & 21 & 0.9 \\
\hline$\underline{\mathrm{P}} 21$ & Short & 48 & 23 & 30 & 55 & 62 & 7 & 0.7 \\
\hline$\underline{\mathrm{P} 22}$ & Short & 11 & 3 & 4 & 12 & 14 & 2 & 0.4 \\
\hline P24 & Short & 35 & 15 & 15 & 36 & 35 & 1 & 0.6 \\
\hline$\underline{\mathrm{P}} 25$ & Short & 77 & 34 & 54 & 96 & 122 & 26 & 1.3 \\
\hline P26 & Short & 18 & 8 & 15 & 25 & 33 & 8 & 0.5 \\
\hline P27 & Short & 7 & 0 & 1 & 8 & 15 & 7 & 0.7 \\
\hline$\underline{\mathrm{P}} 28$ & Short & 22 & 7 & 13 & 28 & 39 & 11 & 1.9 \\
\hline P29 & Short & 21 & 5 & 6 & 22 & 25 & 3 & 1.0 \\
\hline P30 & Short & 0 & 0 & 8 & 8 & 8 & 0 & $\mathrm{n} / \mathrm{a}$ \\
\hline Total & & 1056 & 488 & 852 & 1420 & 1843 & 423 & $0.8 \dagger$ \\
\hline
\end{tabular}

${ }^{\mathrm{a}}$ Estimated by capture-recapture technique. ${ }^{\mathrm{b}}$ Practice list size missing for two practices, so these patients have been excluded from the total (22 patients). 